\title{
LA RECREACIÓN LITERARIA DE UNA VARIEDAD LINGÜÍSTICA: CUENTOS DE BARRO DE SALARRUÉ
}

\author{
The literary representation of a linguistic variety: Cuentos de barro de Salarrué
}

\section{Martha Mendoza*}

\begin{abstract}
RESUMEN
El análisis de un texto literario se puede enriquecer con la identificación de los elementos fonológicos, morfológicos, sintácticos y léxicos utilizados por el autor para recrear la impresión de una variedad lingüística particular con sus características regionales y/o sociales. Al mismo tiempo, el identificar esos elementos nos permite dilucidar la forma en que el autor consigue proyectar una impresión de oralidad en su obra y evaluar su habilidad al hacerlo.

Por tanto, el presente artículo se enfoca en el análisis de las estrategias lingüísticas más sobresalientes que el autor salvadoreño Salvador Salazar Arrué (Salarrué) emplea en su obra Cuentos de barro con el propósito de recrear la variedad lingüística del español salvadoreño, la cual continúa siendo relativamente poco estudiada hasta ahora, y cómo esas estrategias son desplegadas hábilmente por el autor para darle un efecto de oralidad a su prosa.

Palabras clave: lengua española, variedad lingüística, español salvadoreño, dialecto literario, oralidad.
\end{abstract}

\section{ABSTRACT}

The analysis of a literary text can be enriched by the identification of the phonological, morphological, syntactic, and lexical features used to recreate the effect of a particular language variety and its regional and/ or social characteristics. At the same time, identifying such features allows us to gain specific knowledge about how writers project a sense of orality in their prose and how effective they are in doing so.

Thus, this article focuses on the most prominent linguistic strategies employed by El Salvadorian author Salvador Salazar Arrué (Salarrué) in his work Cuentos de barro to represent the speech of this relatively understudied linguistic variety of Spanish and how such strategies effectively contribute to recreate a sense of orality in the author's prose.

Key Words: Spanish language, language variety, El Salvadorian Spanish, literary dialect, orality.

Florida Atlantic University. Department of Languages, Linguistics \& Comparative Literature. United States of America. Correo electrónico: mmendoza@fau.edu

Recepción: 15/1/17. Aceptación: 12/5/17. 


\section{Introducción}

El español de Centroamérica en general, así como el de El Salvador en particular, ha sido escasamente estudiado (Quesada Pacheco y Rivera Orellana, 2013: 141; Quesada Pacheco, 2010: 14; Quesada Pacheco, 2008). Quesada Pacheco concluye que "seguimos sin tener una idea clara y general de cómo se habla el español en esta parte del mundo hispanohablante" (2008: 166). Es indudable, sin embargo, que en esta región existe una gran riqueza dialectal digna de ser investigada más ampliamente. Una manera de explorar esa riqueza es mediante el análisis lingüístico de textos literarios que se propongan retratar el habla de la región. Un ejemplo de este tipo de texto es la obra titulada Cuentos de barro del escritor salvadoreño Salvador Salazar Arrué (Salarrué) (1899-1975), la cual es una colección de narraciones cortas cuyos protagonistas principales son personajes campesinos y/o indígenas que viven en un mundo de pobreza y desamparo. El lector llega a conocerlos por las descripciones del narrador, pero sobre todo a través de los abundantes diálogos en los que participan. Son personajes sencillos que hablan un español regional, popular de El Salvador, el cual refleja su origen humilde. Con el fin de representar un tipo humano que se apegue lo más posible a la realidad, Salarrué crea una representación literaria del dialecto salvadoreño, principalmente por medio de modificaciones de la ortografía del español normativo.

Azevedo (1995: 449-450) argumenta que "the literary representation of dialectal speech may constitute a valuable ancilliary source for the analysis of nonstandard language varieties". Por lo tanto, el análisis lingüístico de una obra literaria como la de Salarrué constituye una herramienta sumamente útil para identificar aquellos elementos fonéticos, morfo-sintácticos y léxicos que contribuyen a la recreación de una variedad lingüística particular, especialmente si esta no es estándar, en este caso el habla rural salvadoreña. A su vez, a partir de la identificación de los elementos específicos de tipo lingüístico utilizados por el autor, se puede además lograr dilucidar la manera en que este consigue evocar la impresión de oralidad que se proyecta en su obra.

Dada la escasez de estudios de tipo lingüístico del español salvadoreño, así como la falta de aplicación de tales estudios a obras de literatura provenientes del área centroamericana, el presente artículo se enfoca en el análisis de las estrategias lingüísticas más sobresalientes desde el punto de vista fonético, morfológico, sintáctico y léxico que aparecen en Cuentos de barro y muestra cómo Salarrué utiliza esas estrategias con gran efectividad para recrear la variedad hablada del español salvadoreño, lo cual nos permite asomarnos al mundo donde se desenvuelven los personajes caracterizados, a la vez que confiere un efecto de oralidad que está presente en toda la obra y que se transmite al lector.

Con el fin de recrear la variedad lingüística en cuestión, el autor recurre a la creación de un dialecto literario, definido por Ives (1971: 146) como "an author's attempt to represent in writing a speech that is restricted regionally, socially, or both"; sin embargo, como observa Azevedo, toda creación literaria es necesariamente una imitación del habla real ya que "literary dialect does not seek to replicate speech but rather to emulate it through a strategy of foregrounding specific features, mimetically generating a heteroglossic discourse to evoke orality" (2002: 510). Pero para que la recreación de una variedad dialectal plasmada en una obra literaria tenga sentido para el lector, se requiere contrastar tal variedad con la variedad considerada como normativa. Por lo tanto, la representación de los rasgos dialectales en la obra de Salarrué presupone el marco del español normativo, el cual es objeto de diversas modificaciones, especialmente de carácter ortográfico, las cuales ayudan a retratar las diferencias regionales o sociales que caracterizan la variedad lingüística representada. Como explica Azevedo (1991: 125), "Writers have traditionally employed dialectal or social features of language to portray regional and/or social linguistic differences, thus making nonstandard pronunciation, morphosyntax, or vocabulary stand out against the backdrop of the standard language as a kind of marked 
speech for specific stylistic purposes”. Así, en las páginas siguientes veremos cómo Salarrué despliega diversos recursos lingüístico-literarios que le permiten crear el efecto de oralidad que se percibe al leer sus cuentos.

\section{Rasgos fonéticos}

Las alteraciones fonéticas que aparecen como parte del dialecto representado en Cuentos de barro son variadas. Al no contar con el recurso lingüístico de la transcripción fonética, el autor recurre a la modificación de la ortografía para representar las diversas variantes que se dan en la pronunciación. Estas modificaciones, aunque especialmente visibles, de hecho no son las únicas ni las más representativas del habla que se presenta en la obra, pues muchas de ellas se producen en todas las hablas populares del mundo hispánico o por lo menos no son exclusivas del habla de El Salvador. Se podría argumentar que quizá rasgos morfosintácticos como el voseo y el uso del pronombre personal de sujeto después de preposición (e.g. contra yo) son más significativos como características definitorias de esta variedad regional del español, aunque, por otra parte, lo que sobresale en una obra literaria como la que se discute aquí es la impresión total lograda a través de la idónea combinación de diversos rasgos, tanto fonólogicos como morfosintácticos y léxicos. Enseguida nos enfocamos en los procesos consonánticos y vocálicos más prominentes que se pueden encontrar en Cuentos de barro.

\subsection{Procesos consonánticos}

Hay un gran número de procesos fonológicos que afectan diferentes consonantes, tales como los siguientes:

La sustitución de la fricativa labiodental sorda /f/ por la fricativa velar sorda /x/: ajuera ${ }^{1}$ 'afuera', conjundir 'confundir', dijunto 'difunto', jierro 'fierro', jlor 'flor', jrío 'frío', jué 'fue', juerte 'fuerte', juerzas 'fuerzas', juimos 'fuimos', jumándose 'fumándose', morgina 'morfina', perjumándolo 'perfumándolo', projundos 'profundos'. En la ortografía Salarrué utiliza tanto la letra $g$ como la $j$ para representar este rasgo. En el caso de los grupos resultantes [xr] y $[\mathrm{xl}]$, nos encontramos ante secuencias de sonidos en general inadmisibles en español. Sin embargo, el autor, en una nota explicativa, afirma que "La $\mathrm{J}$ es muy a menudo usada, en la prosodia del campesino salvadoreño, en lugar de la F y de la H: jlores por flores, jierro por fierro, esta última forma arcaica-pero corriente-de hierro" (Salarrué, 1967: 195).

La sustitución de la nasal alveolar /n/ por la nasal palatal $/ \mathrm{n} /$, especialmente al inicio de palabra: añudada 'anudada', ñebla 'niebla' (con palatalización), ñeblina 'neblina', ñevosos 'nevosos', ñublado 'nublado'.

El intercambio de consonantes graves (bilabiales y velares): en particular, la sustitución de la oclusiva bilabial sorda /p/ por la oclusiva velar sorda /k/: cuede 'puede', cuedo 'puedo', y la de la oclusiva bilabial sonora /b/ por la oclusiva velar sonora $/ \mathrm{g} /$, especialmente a principio de palabra: güelta 'vuelta', güelto 'vuelto', güelva 'vuelva', güelvo 'vuelvo', güena 'buena', güeno 'bueno', morigundo 'moribundo'.

La epéntesis de la fricativa palatal sonora /j/ entre dos vocales: alegriya 'alegría', burbujeyo 'burbujeo', creya 'crea', deseyo 'deseo', diya 'día', feyo 'feo', friyo 'frío', Garciya 'García', Mateyo 'Mateo', ondeya 'ondea', seya 'sea', Tadeyo 'Tadeo', tanteyo 'tanteo'. La epéntesis de /j/ se da solamente en caso de que aparezcan dos vocales en hiato y su función es precisamente romper el hiato.

La adición de una consonante al principio de palabra (prótesis) o en medio de palabra (epéntesis): aigre 'aire', ambuleto 'amuleto', arronjó 'arrojó', Berlice 'Belice', dentró 'entró', descurría 'escurría', destertores 'estertores', lambía 'lamía', rebalsó 'rebasó', trompezándose 'tropezándose'. Aunque no siempre es así, la consonante que se agrega por epéntesis generalmente es homorgánica; en posición inicial de palabra, la consonante protética es la $/ \mathrm{d} /$.

La pérdida de la oclusiva dental sonora /d/: Davi 'David', e 'de', felicidá 'felicidad', mercé 'merced', mitá 'mitad', onde 'donde', seguridá 
'seguridad', voluntá 'voluntad', usté 'usted'. La omisión ocurre sobre todo en posición final de palabra y a menudo con la preposición de. En tal caso, la ortografía de las palabras agudas sufre una segunda modificación al agregárseles el acento escrito. En su estudio sobre la fonética del español salvadoreño, Azcúnaga López (2010: 94) afirma que se observa la pérdida de /d/ en expresiones con de y en posición final absoluta, dando así confirmación a lo representado por Salarrué en su obra.

La pérdida de la fricativa palatal sonora /j/ intervocálica después de la vocal alta /i/ acentuada, con la consecuente creación de un hiato: blanquio 'blanquillo', carretía 'carretilla', Felipio 'Felipillo', piojio 'piojillo'. Canfield (1988: 62) corrobora la existencia de este fenómeno en el habla de El Salvador al afirmar que "La /y/ intervocálica de El Salvador, como las de toda Centroamérica (...) no es tensa y a menudo se convierte en una semivocal o puede incluso desaparecer: silla [sía], bella [béa] dándose muchos casos de hipercorrección".

La pérdida de la fricativa alveolar sorda /s/ en posición final de sílaba: jójoro 'fósforo', juguémola 'juguémosla', pué 'pues', etc., rasgo por lo demás bastante extendido por todo el mundo hispánico (cf. Zamora Munné y Guitart, 1982; Canfield, 1981; Moreno de Alba, 1993).

La neutralización de las líquidas /1/ y /r/: arquiló 'alquiló', carculado 'calculado'. Al igual que en otras variedades del español, como las hablas del Caribe, la neutralización ocurre siempre en posición final de sílaba. Sin embargo, los ejemplos en Cuentos de barro son únicamente de rotacismo y no de lambdacismo.

La sustitución de las consonantes /d/ y /g/ por una consonante líquida: alvertía 'advertía', arvertiste 'advertiste', irnorante 'ignorante', parpareaban 'parpadeaban'.

La simplificación de grupos consonánticos: estinto 'instinto' (con descenso de la primera /i/), ivierno 'invierno', oservado 'observado', persinó 'persignó'. En este tipo de ejemplos, la simplificación siempre ocurre en la coda silábica, por lo que cuando hay una sola consonante en la coda esta queda eliminada, mientras que dos consonantes en esa posición se reducen a una.

La aversión de la lengua española por ciertos grupos de consonantes se refleja también en el proceso de vocalización de consonantes, por ejemplo: reuto 'recto', que tiene como resultado la simplificación del grupo $/ \mathrm{kt} /$ al cambiarse la $/ \mathrm{k} /$ por /w/. Históricamente, la vocalización es un proceso que ha estado presente desde los inicios del idioma mismo, como puede observarse en el caso de una palabra como deuda, proveniente del latín dēbita (con vocalización de /b/) (Penny, 1991: 78).

La aspiración de $h$ ortográfica: albajaca 'albahaca', jaz 'haz', jedía 'hedía', jediondo 'hediondo', jelada 'helada', juelgo 'huelgo', juraco 'huraco'. En algunos casos, esta aspiración podría tratarse de la conservación a nivel dialectal de la antigua aspiración proveniente de la /f-/ inicial latina: /f/ > /h/ >ø (cf. Latín farina $>$ español harina).

Hay que hacer notar además la presencia en el español salvadoreño de la consonante fricativa (alveo)palatal sorda [J]—ortográficamente $s h$ - que se da especialmente en los términos de origen náhuatl: egóishta 'egoísta', huishte 'trozo de vidrio', maishtro 'maestro', murusho 'de cabello muy rizado', shashaco 'comido de viruelas, carcomido'.

El yeísmo (uso de $y / \mathrm{j} /$ por $l l / K /$ ): amariya 'amarilla', blanquiyos 'blanquillos', oriya 'orilla', pitiyo 'pitillo'. En este caso, la alteración de la ortografía no es más que otro ejemplo de dialecto visual (eye dialect $)^{2}$ pues no señala ninguna desviación con respecto a la pronunciación normativa del español de América, ya que el español americano, incluyendo el salvadoreño, en general es yeísta (Zamora Munné y Guitart, 1982; Moreno de Alba, 1993). Sin embargo, una vez más, esto es una clara indicación de que la variedad retratada no es la estándar $\mathrm{y}$, por ende, tanto esta como sus hablantes ocupan una posición subordinada en la sociedad salvadoreña; como apunta Mendoza (2014: 113), "since readers associate normative spelling with correctness, the spelling modifications further underscore the contrast between the dominant discourse of normative Spanish 
and the subordinate discourse of the dialectal variety". Y es quizá el encontrarse con palabras ortográficamente "mal escritas" lo que impacta al lector más que ningún otro rasgo de una obra dialectal como la de Salarrué.

\subsection{Procesos vocálicos}

Aunque las vocales del español no presentan el mismo grado de variación de una región a otra que las consonantes, Salarrué en su obra representa diversas alteraciones que involucran a las vocales. Estos fenómenos vocálicos una vez más ponen de manifiesto que se trata de un habla alejada de la normatividad y hermanada con la oralidad del habla coloquial. A continuación, veamos los más representativos.

La formación de deslizadas es un proceso fonológico del español normativo que afecta a toda vocal alta inacentuada en contacto con cualquier otra vocal; sin embargo, en el habla representada aquí, como en muchas hablas populares, este proceso afecta no solo a las vocales altas $/ \mathrm{i} / \mathrm{y} / \mathrm{u} /$, sino también a las medias átonas /e/ y /o/, las cuales sufren la elevación a vocales altas al estar al lado de otra vocal. La diptongación ocurre tanto en interior de palabra como en la frontera entre diferentes palabras: coliando 'coleando', diadentro 'de adentro', diaire 'de aire', dioro 'de oro', diun 'de un', golpiada 'golpeada', liace 'le hace', liaga 'le haga', lián 'le han', miás 'me has', nuai/nuay 'no hay', nues 'no es', pantión 'panteón', quiapunta 'que apunta', rodiado 'rodeado', sihacen 'se hacen', tei 'te he', voltió 'volteó', vuá 'voy a' (con pérdida de la deslizada [j] y transferencia del acento). El fenómeno de la eliminación de hiatos y su transformación en diptongos es uno de los más frecuentemente representados en Cuentos de barro; ${ }^{3}$ además si se trata de dos palabras distintas, Salarrué las representa ortográficamente sin ningún espacio entre ellas, como si fueran una sola.

Se encuentra también el cambio en la posición del acento prosódico: ái 'ahí', amonós 'vámonos', baul 'baúl', caido 'caído', destruido 'destruído', egóishto 'egoísta', hombré 'hombre', máis 'maíz', mama 'mamá', óido 'oído', ráiz 'raíz', traido 'traído'. Con frecuencia, la consecuencia de la transferencia del acento es precisamente la diptongación, la cual tiene como resultado que se reduzca el número de sílabas en la palabra.

Otros cambios vocálicos presentes en la obra de Salarrué son:

La adición de vocales en medio o al final de la palabra: apriesa 'a prisa', cadábere 'cadáver'.

La diptongación de la vocal /o/: embruecadiza 'embrocadiza', güelía 'olía', güeliera 'oliera', güeltereta 'voltereta'. Esto posiblemente representa la sobre-extensión de la diptongación de la antigua vocal breve /ŏ/ proveniente del latín (cf. Penny, 1991: 43-47).

La elevación de las vocales átonas medias /e/ > /i/, /o/ > /u/: arripienta 'arrepienta', asigún 'a según', disgraciado 'desgraciado', ductores 'doctores', hindidura 'hendidura', inano 'enano', incontrado 'encontrado', istúpida 'estúpida', ixaminé 'examiné', pulicía 'policía', ricién 'recién', siñor 'señor', umbligo 'ombligo', uservó 'observó'. Es interesante notar que, en datos recientes provenientes de El Salvador, Azcúnaga López (2010: 88-89) encuentra la elevación (cierre vocálico) de /e/ a /i/ y de /o/ a /u/, pero solamente en posición final de palabra y final de sílaba ante /-S/ y no en las posiciones mostradas por Salarrué (por ejemplo, en sílaba inicial), lo cual parecería indicar una extensión más amplia de este fenómeno en la variedad retratada en Cuentos de barro.

El descenso de la vocal alta anterior /i/: emagínese 'imagínese', endeviduo 'individuo', engrato 'ingrato', mesmamente 'mismamente', mesmo 'mismo', presepicio 'precipicio'. En algunos de estos ejemplos, quizá se podría hablar de una especie de armonía vocálica, pues la vocal siguiente es generalmente una vocal [alta] (media o baja). Así, la [i] al descender a [e] se acerca al punto de articulación de la vocal siguiente.

La adición de la deslizada palatal [j]: $e i$ ido 'he ido', ei incontrado 'he encontrado', héi oservado 'he observado', luei visto 'lo he visto', méi fijado 'me fijado'. Este fenómeno ocurre solo en palabras monosilábicas de categorías 
gramaticales cerradas como pronombres y el verbo auxiliar haber.

\subsection{Otros cambios}

A lo largo de las páginas de Cuentos de barro, aparecen asimismo algunos otros procesos que afectan tanto a vocales como a consonantes, por ejemplo:

La pérdida de vocales o sílabas enteras: Puede darse la ausencia de una o hasta dos sílabas. La sílaba o sílabas omitidas ocurren, generalmente, ya sea al inicio o al final de la palabra. También puede observarse que la pérdida, aunque se da en distintas clases de palabras, sucede especialmente en términos de alta frecuencia como verbos auxiliares y artículos: ber 'haber', bia 'había', bieras 'hubieras', bís 'habís', calofriyo 'escalofrío', compa 'compadre, compañero', currucado 'acurrucado', hora 'ahora', lagua 'el agua', lonra 'la honra', lúnico 'lo único', maginaba 'imaginaba', mano 'hermano', masonas 'amazonas', monós 'vámonos', muchá 'muchachos', ña 'niña, señora', ño 'niño, señor', pa 'papá, para', paludís 'paludismo', rír 'reír', taba 'estaba', tate 'estate', trés 'traes', Ulalio 'Eulalio'.

Metátesis: murciégalo 'murciélago', naide 'nadie', paderón 'paredón', tubreculosa 'tuberculosa'.

Aunque el encadenamiento entre palabras tampoco representa una característica exclusiva del dialecto salvadoreño, el autor, como se mencionó antes, frecuentemente omite el espacio ortográfico entre palabras como un recurso más para retratar el lenguaje oral: derrepente 'de repente', laija 'la hija', laisla 'la isla'.

En resumen, todas estas diferentes desviaciones de la ortografía estándar del español sin duda constituyen un recurso visual muy efectivo para enfatizar que se trata de una variedad coloquial, espontánea e informal del habla oral.

\section{Rasgos morfológicos}

Al analizar la morfología de Cuentos de barro observamos fenómenos muy particulares que, al igual que los fonológicos, contribuyen a recrear la impresión literaria del dialecto salvadoreño. Los que pueden ser considerados como los más sobresalientes son los siguientes:

La adición de prefijos: adémelo ' $a+$ démelo', afijese ' $a+$ fíjese', alléveme ' $a+$ lléveme', arrecuérdese ' $a+$ recuérdese', atrompesándose ' $a$ + tropezándose', descruzar 'des + cruzar', desescondido 'des + escondido', rempujá 're + empuja'. Los prefijos usados son sobre todo $-a$, -des y -re, cuyo empleo no coincide con el del español normativo.

La presencia de arcaísmos: semos 'somos', vido 'vió', los cuales hasta el presente continuan existiendo en el habla salvadoreña, aunque sobre todo en zonas alejadas de San Salvador, la capital, y entre las personas mayores de 60 años (Quesada Pacheco y Rivera Orellana, 2013: 161-162).

Existe analogía, con retracción del acento: En el imperfecto de indicativo los verbos de la segunda y la tercera conjugaciones en $-e r$ e -ir toman las terminaciones de la primera conjugación en -ar. Ejemplos: caiban 'caían', oiba 'oía', reiba 'reía', sonreiba 'sonreía', traiba 'traía'.

Además ocurren modificaciones en cuanto al género gramatical de las palabras: por ejemplo, la extensión del género: animala 'animal (femenino)', egóishto 'egoísta (masculino) ${ }^{4}$ y el cambio de género con respecto al español estándar: la color 'el color'.

\subsection{Derivación}

Hay una abundante muestra de procesos de derivación mediante los cuales se crean nuevas palabras, utilizando diversos afijos con resultados que no se encuentran en el español normativo y que le dan a esta variedad un sabor muy peculiar. A continuación, se dan algunos ejemplos: cargante 'cargador', clarencia 'claridad', desmando 'desmán', dorisca 'casi dorada', ganchada 'bofetada', güevazo/ huevazo 'golpe, gran cantidad de', jumazón/ humazón 'humareda', palazón 'grupo de ramas o árboles', pitero 'flautista', quinzona 'quinceañera', ramalada 'conjunto de ramas', 
ramazal 'conjunto de troncos y ramas', rogación 'procesión religiosa', rogante 'miembro de una procesión religiosa', ruidal 'ruido excesivo', sobador 'masajista', sombrial 'colectivo de sombra', tramazón 'entrecruzamiento, trabazón', trancazón 'obstrucción', tristoso 'triste', tristura 'tristeza', uyasón/aullazón 'colectivo de aullido', venadiante 'cazador de venados', virazón 'velocidad', yelasón/hielazón 'helamiento, helada', zopilotada 'colectivo de zopilote'. Como se observa en los ejemplos, se encuentran en especial sufijos nominalizadores (cf. Miranda, 1994) como -ada, $-a l,{ }^{5}$-ante y-azón $(<-a z o+-$ ón), los cuales se utilizan para formar sustantivos derivados de otros sustantivos o de verbos.

\subsection{Diminutivo}

Existe igualmente un amplio uso de los diminutivos, tanto en los diálogos como en las secciones narrativas. Los diminutivos no solo funcionan como expresión de disminución, sino también con función afectiva y de cortesía (cf. Mendoza, 2005). Su constante uso acerca lo representado en la obra al lenguaje hablado puesto que se consideran típicos de la interacción oral (Azevedo, 2004: 468) y un rasgo característico del habla familiar e informal, como en los ejemplos a continuación:

"Entre los ladrillos verdosos, las rueditas de plata de las goteras se habian hecho hongos" (Salarrué, 1967: 32).

"En la escurana, las candelas pintaban claror con sus brochitas azules" (ibid: 50).

"y en la oquedad de la casita de madera y lámina se oía el aparatito del telégrafo (...)" (ibid: 74).

"Era quinzona, rubita, gordita, nalgona (...)" (ibid: 78).

“- ¡Mijo, mi lindo!... Perdonáme, cosita; taba como loco!..." (ibid: 94).

"El sol, doradito, se despenicaba por todos lados, como jlor de guachipilín. Los chejes llamaban a puertas y ventanas de casitas que nadie abría nunca: 'tak, tak'..." (ibid: 112).

“-Endeveritas, mi sargento...” (ibid: 148).
En cuanto a las palabras a las que se agrega el diminutivo, entre ellas predominan los sustantivos (aparatito, brochitas, rueditas, etc.) y los adjetivos (doradito, gordita, rubita, etc.), aunque se pueden encontrar también algunos casos como endeveritas donde el diminutivo aparece agregado a un adverbio. Como se puede apreciar, los ejemplos de diminutivos son abundantes y el sufijo utilizado es siempre -ito. Esto coincide precisamente con los resultados del estudio de Quesada Pacheco y Rivera Orellana (2013: 156), que muestran a -ito como el sufijo diminutivo predominante en los datos recabados por ellos sobre El Salvador.

\subsection{Voseo}

Una de las características más notorias y peculiares del habla representada en Cuentos de barro es el voseo. El término voseo se refiere al uso de vos como pronombre de segunda persona singular para el tratamiento familiar e informal, acompañado de formas verbales arcaicas correspondientes a la segunda persona plural, de los pronombres te y vos (que sustituye a $t i)$ y de los adjetivos posesivos $t u$ y tuyo. En las Américas, vos se emplea en muchas regiones como el pronombre de tratamiento informal predominante o en competencia con tú (Penny, 1991: 124-125). En la obra, hay abundancia de ejemplos:

“-(...) Vos vas arando y iplosh!, derrepente pegás en la huaca, y yastuvo; tihacés de plata" (Salarrué, 1967: 12).

"-Me vuá quedar con vos atrás, y te golvés..." (ibid: 44).

“-Date priesa, si querés que te les den algo a los cipotes" (ibid: 61).

"-Decíle al Nicho que no liaga tanta fiesta" (ibid: 82).

“-Decís bien, es el Contagio..." (ibid: 83).

"-Cuando vos naciste taba lloviendo tieso..." (ibid: 90).

“-Andá, hombré (...) y sólo a vos te aguarda" (ibid: 91).

“-Amonós, vos; ya se calmó” (ibid: 91).

“-iPerdoname, hermano!” (ibid: 92). 
“-iNo cuede ser (...) no cuedo vivir sin vos!" (ibid: 95).

Respecto al uso del voseo en esta obra de Salarrué podemos hacer las siguientes observaciones generales: Los padres utilizan vos, y a veces usted, al dirigirse a sus hijos. En cambio los hijos muestran su deferencia y respeto al dirigirse a sus padres solo con usted. En general, las personas de mayor edad vosean con los más jóvenes y estos solamente usan usted para dirigirse a los mayores. Igualmente se usa vos para dirigirse a Dios, los santos, los objetos y los animales. A los desconocidos se les trata de usted, a menos que se ocupe una posición socioeconómica superior. Asimismo, entre compadres se utiliza usted. Hay que notar también que, a pesar de que la edición de Cuentos de barro analizada data de hace ya cinco décadas, los datos sobre el uso de vos encontrados aquí en su mayoría coinciden con los hallados en una época mucho más reciente por Quesada Pacheco y Rivera Orellana (2013).

\section{Recursos sintácticos}

En las obras literarias es frecuente encontrar la manipulación o alteración de la sintaxis para recrear cierta realidad y provocar un determinado efecto en el lector. En el caso de Cuentos de barro, por medio de los diversos recursos lingüísticos desplegados, el efecto de oralidad impregna toda la obra. En ella hablan el indio, el negro, el pescador, el campesino, la prostituta, la madre. Para dar paso a estas voces, en los cuentos aparecen fenómenos sintácticos no normativos que ayudan a definir de una manera más precisa el habla de los salvadoreños que los protagonizan. Como ejemplos tenemos los siguientes:

La concordancia del objeto directo con el verbo impersonal haber, por reanálisis del objeto directo como sujeto: brán tamagases 'habrá tamagases'; habrán hoyitos 'habrá hoyitos', aunque esto es definitivamente algo común en toda Latinoamérica. ${ }^{7}$
El uso del pronombre personal de sujeto como objeto de preposición: contra yo 'contra mí'; síganme a yo 'síganme a mí'.

El uso del infinitivo en función de imperativo:

“-iIrte, irte de mi lado, engrato (...)!" (Vete, vete de mi lado, ingrato) (Salarrué, 1967: 162).

"-Devolverlo vos, si tanta gana tenés" (Devuélvelo tú, si tanta gana tienes) (ibid: 167).

La inversión del orden canónico de los pronombres átonos, ${ }^{8}$ la cual Stewart (1999: 108) describe como "non-standard (principally rural stigmatized)":

“-(...) a vos te se jué hecha la ofensa" (Salarrué, 1967: 92).

La pluralización del pronombre de objeto directo con referente singular:

“-(...) Todo el barrido de la mula se los echo (...)” (Salarrué, 1967: 154).

Con respecto a este punto, Stewart (1999: 107) observa que "As the plural is ambiguous in the indirect object pronoun se there is a tendency to add the plural to the direct object pronoun (se los/se las) even when it is logically singular"; el ejemplo presentado aquí se refiere a echar abono (el barrido de la mula) a unas flores, por lo que en este caso lo normativo sería decir: 'todo el barrido de la mula se lo echo' con el pronombre lo en singular.

\subsection{Repetición de elementos y paralelismo sintáctico}

Otro recurso de la narrativa con apariencia de oralidad es el uso de la repetición y la reiteración de elementos en el discurso (Tannen, 1982; Tannen, 1987) dado que, como explica Tannen, "repetition, which is artfully developed and intensified in literary discourse, is spontaneous, pervasive, and often relatively automatic in conversation" (1987: 580-581). En Cuentos de barro existen innumerables ejemplos en los que se repiten elementos oracionales, ya sean verbales, nominales o adjetivales:

“-iAh..., no señor..., nuai tales carneros, aloyé, ${ }^{9}$ nuai tales!... Siesque vinieron 
los "managuas", despacito... y cerraron las puertas cuendo era al mediodía, aloyé (...) Sestá pudriendo diambre: ya giede, aloyé, iya giede!" (Salarrué, 1967: 30).

"Iban, iban ..., en silencio, tranqueando por la calle polvorosa que, como una culebra, tenía piel a manchas de sombra y luz (...) Pasaron en fila. Iban, iban..." (ibid: 60-61).

“-La ña Gabriela taba quejándose, y se jué callando, y se jué callando, y se jué callando..." (ibid: 71).

"Se quejaba, se quejaba y no podía dormir. El enfermero le puso morgina; y él soñó clarito, clarito, que llegaba a su casa (...) De su cuerpo caiba un aserrín colorado, colorado (...)" (ibid: 114).

"Detrás estaba el convento (...) sostenido por un pilar, otro pilar, otro pilar" (ibid: 127).

$\mathrm{La}$ repetición de elementos en el discurso tiene que ver no solamente con la mera duplicación de componentes léxicos sino que funciona a nivel de la estructuración y la organización de las oraciones, en las cuales existen paralelismos sintácticos, y también funciona a nivel semántico, al retomarse ideas ya expresadas por medio de palabras pertenecientes al mismo campo semántico o a alguno relacionado. Además, de acuerdo con Baixauli Fortea (2000: 92), "conviene subrayar la importancia de la repetición como elemento de cohesión, tanto en la narración en general, como en el relato conversacional en particular".

Asimismo, con frecuencia las oraciones son breves y se suceden sin subordinadores o conectores, en yuxtaposición, proyectando la apariencia de lengua hablada. ${ }^{10}$ Turner (1973: 71) comenta la relación entre las oraciones simples en las obras escritas y el lenguaje oral de la siguiente manera: "Early and popular writing in any country is close to spoken style, with loose paratactic sentences (in which the clauses are simply laid alongside each other, as in 'Never venture, never win')". En Salarrué tenemos ejemplos múltiples de yuxtaposición, en los que las proposiciones se presentan una al lado de la otra sin que se haga explícita la relación que guardan entre sí y, a la vez, se observa un paralelismo sintáctico que crea un ritmo propio de lo oral, como se advierte en los ejemplos a continuación:

"Pero Honduras es honda en el Chamelecón. Honduras es honda en el silencio de su montaña bárbara y cruel; Honduras es honda en el misterio de sus terribles serpientes, jaguares, insectos, hombres..." (Salarrué, 1967: 25).

"José Pashaca era un cuerpo tirado en un cuero; el cuero era un cuero tirado en un rancho; el rancho era un rancho tirado en una ladera" (ibid: 11).

"Todo se doraba; todo se caía; todo se tostaba" (ibid: 143).

Analizando el paralelismo sintáctico, Tannen (1982: 7) señala lo siguiente: "[syntactic parallelism] is perfectly geared to knowing through involvement (as discussed earlier), which underlies both oral performance and conversation". Puesto que el empleo de construcciones paralelas (e.g. SN Vcop SAdj; SN Vcop SN; SN V) y la repetición (e.g. Honduras es honda... Honduras es honda... Honduras es honda) son característicos del lenguaje oral, su inclusión en esta obra manifiesta claramente el intento del autor por representar el habla real.

\subsection{Omisión de elementos}

En el aspecto sintáctico, además de los fenómenos ya anotados, cabe mencionar la recreación de la oralidad en el habla de los personajes y en la narración misma mediante otros recursos que se combinan para producir un efecto general de discurso oral. Por ejemplo, la omisión de elementos como preposiciones, verbos y pronombres, que ocurre abundantemente en el lenguaje oral, se encuentra con frecuencia en el texto. Así, aparecen frases como las siguientes:

"-No puedo, tata, mucho yelo..." (Salarrué, 1967: 24), en la cual el verbo hay es omitido.

"-¿Conque, embrujada, eh?... -iNo creya Padre, entuavía sioye un bisbiseyo!..." (ibid: 33), donde se sobreentiende el verbo estar como parte de la primera frase-[está] embrujada - mientras que la segunda se podría completar así: No creya Padre [que no está 
embrujada]; o bien, interpretarse con omisión del pronombre lo: No [lo] creya Padre.

En el ejemplo: "- -Andá onde Lino, que te venda un cuis de esencia de azar (...)" (ibid: 71), se sobreentiende la omisión de un verbo y de un pronombre clítico: [dile o pídele] que te venda..., o la de una preposición: [para/pa] que te venda...

En el caso de "Les ofreció taburete" (ibid: 173) hace falta un artículo.

En “-iAchis!... ¿Y qué me querrá el maishtro?" (ibid: 91), la preposición para no se incluye: ¿Y [para] que me querrá el maishtro?

Otro rasgo que podemos mencionar es la elipsis (indicada en la obra por medio de puntos suspensivos), la cual refleja, asimismo, formas de expresión que encontraríamos en un contexto oral:

"Los viejos de quijada de plomo cabeceaban, como diciendo: -Pa que veyan..." (Salarrué, 1967: 39-40).

"-Esos han sido los Garciya. —O los Munto. —Hilario y Cosme, quizá...” (ibid: 40).

"-Léi traido para ver si usté le quita la puya. Pueda ser que una sobada..." (ibid: 98).

En todos estos ejemplos, hay elementos oracionales que se han dejado fuera, los que no siempre pueden recobrarse del contexto narrativo pero que nos recuerdan las pausas y vacilaciones del discurso oral.

Todas estas modificaciones y omisiones de elementos impregnan de oralidad lo representado en la obra, a la vez que sirven para subrayar el carácter marginal de estos hablantes frente a los hablantes del español considerado estándar. En las palabras de Azevedo (1995: 450): "In a literary context, vernacular features have traditionally served to underscore the marginal condition of nonstandard talk and its speakers", por lo cual el análisis de un dialecto literario también puede ser muy útil para mostrar "relationships between language and power, marginalization and social exclusion, and the role of language variation in the formation and maintenance of social hierarchies and cultural ideologies" (Azevedo, 2002: 505).

\section{Deixis}

Martínez Ruiz (2000: 244) define la deixis como una categoría pragmática que se refiere a "la localización e identificación de personas, objetos o eventos de los que se habla en relación con el contexto espacio-temporal creado y sostenido por la enunciación y por la participación de un hablante y un oyente". Al emplear términos deícticos, Salarrué establece un puente entre el texto y la realidad extralingüística, como si se esperara que el lector estuviese presente en los hechos narrados:

"-Era un endizuelo así, sapito, con buche y con una cosa feya aquí. —¿Onde? Aquí..." (Salarrué, 1967: 80).

El deíctico aquí exige el estar presente en la escena que se desarrolla, pues de otra manera no es posible darle una interpretación. Por lo tanto, el anclaje del deíctico en la narración requiere una participación más directa del lector, forzándolo a interpretarlo según la deixis sugerida, y lo remite a un mundo pleno de oralidad dado que esta forma de expresarse es típica de una interacción cara a cara. Así lo reconoce Martínez Ruiz (2000: 259) cuando afirma que en la conversación coloquial es "donde la deixis alcanza sus más altos índices de empleo, entre otros factores, porque nos hallamos ante un tipo de interlocución inmediata, cara a cara (...)".

\section{Rasgos léxicos}

El léxico de Cuentos de barro es de gran riqueza y abundancia, por lo que sería imposible tratar de estudiarlo en detalle en un trabajo como este. Sin embargo, se pueden hacer varias observaciones relevantes en cuanto a las características principales del léxico que aparece en la obra. Muchas palabras del español normativo se modifican semánticamente adquiriendo nuevos significados que se suman a los antiguos o los reemplazan completamente. Tal es el caso de palabras como las que a continuación se mencionan: ${ }^{11}$ arresto 'esfuerzo', batidor 'pequeña vasija de barro', bolo 'borracho', 
bravo 'enojado', brusca 'prostituta', cacho 'cuerno, mango de cuerno', carburo 'palabrería sin sentido', cazar 'descubrir', cobija 'miedoso', corvo 'machete', encaje 'ingle', espiar 'dar un vistazo', gato 'bíceps', goma 'resaca', guiño 'tirón', ido 'distraído, trastornado', luego 'pronto', manga 'manta, cobertor', monte 'hierba', palo 'árbol, madera', patente 'cercano', península 'penitenciaría, cárcel', pelotero 'alegre', petaca 'joroba', poza 'remanso de un río', prender 'encender', pringar 'lloviznar', sazón 'verde (fruta)', silencio 'quieto, callado', tanto 'cantidad', tarro 'recipiente hecho con media calabaza', tinto 'rojo', tirar 'engañar', topar 'aceptar, querer', voltear 'volver'.

De una manera bien lograda el autor imprime un toque costumbrista a su obra por medio de la gran cantidad de salvadoreñismos utilizados. Es evidente que muchos de los nombres de objetos, plantas y animales se han tomado directamente del habla de la región. No solo los diálogos sino también las descripciones de los personajes y el ambiente contienen un lenguaje coloquial y lleno de regionalismos, como en los dos ejemplos siguientes:

"Alguien seguía bañándose en el patio, a guacaladas. Dulcemente volvió a cerrarse la puerta de la esquina, guardando los olores: olor a maicillo, olor a petates, olor a manta y a cambray pirujo (...)" (Salarrué, 1967: 72).

"El negro Nayo había llegado a la costa dende lejos. Sus veinte años, morados y murushos, reiban siempre con jacha fresca de jícama pelada" (ibid: 177).

El uso de términos como guacalada o murusho también contribuye en gran medida al efecto de oralidad que el lector percibe al leer la obra. Sin embargo, hay que mencionar que es muy significativo el hecho de que Salarrué haya incluido un glosario explicando los elementos léxicos de uso regional, sin el cual podría ser un tanto difícil la comprensión del texto para un lector ajeno a esta experiencia. Esto además constituye un testimonio claro de las considerables diferencias lingüísticas que pueden llegar a existir entre las distintas variedades del español.

\subsection{Nahuatismos}

Hay que hacer notar que muchas de las palabras que aparecen en los cuentos provienen del idioma náhuatl, hablado en tierras salvadoreñas antes de la llegada de los españoles. A continuación se ofrecen algunos ejemplos de los nahuatismos que se presentan en la obra, con sus respectivas definiciones: ${ }^{12}$

Chele, blanco, rubio. De selic 'verde, tierno': “(...) iba un chele vestido dentierro (...)" (Salarrué, 1967: 140).

Cherche, pálido, verdoso. De selic 'verde, tierno': "Se puso cherche, cherche" (ibid: 93).

Chipe, pobre, arruinado. De shipehua 'pelar, desollar': “(...) están todos mero chipes...” (ibid: 154).

Choco, ciego, tuerto. De choca 'llorar': “-(...) A nosotros los chocos nos encamina el estinto (...)" (ibid: 68).

Choya, pereza, lentitud. Probable nahuatismo: "-Apurá el paso, vos; ende que salimos de Metapán trés choya" (ibid: 23).

Chucho, perro. De chichita 'perro': "Un chucho, que llegó un día a oler la casa, salió (...)" (ibid: 31 ).

Cipote, niño, muchacho. De sepocti 'desvalido, entumido': “(...) con su brazo amplio protegía al cipote" (ibid: 90).

Murusho, de cabello muy rizado. De muluchtic 'lana mullida, cabello crespo': "Sus veinte años, morados y murushos (...)" (ibid: 177).

Nana, madre. De nanti 'madre': “(...) quería a la Juana como si hubiera sido su nana" (ibid: 19).

Neshne, renegrido, ceniciento. De neshti 'ceniza': "El negro Calistro y su compañero miraron curiosos al endeviduo neshnito (...)" (ibid: 68).

Pacho, de poco fondo, aplastado. De pachoa 'aplastar': “(...) y en la corriente pacha, quebradita y silenciosa, rodaban piedrecitas de cal" (ibid: 18).

Peche, flaco, delgado. De pechtic 'delgado, flaco': “(...) una cosa rara se fue manifestando en la peche María" (ibid: 100). 
Pepenar, recoger. De pehpena 'recoger': "El la pepenó (...)" (ibid: 54).

Pushco, sucio. De pushti 'moho', co 'lugar': "Daba la impresión de bañada, dentro del traje pushco y jediondo" (ibid: 78).

Shashaco, comido de viruelas, carcomido. De chachacuactic 'dentado': "El shashaco Tadeyo llegó apriesa onde Pedrón" (ibid: 91).

Shuco, sucio, agrio. De shucuc 'agrio, fermentado': “(...) olisquiando el jediondo del río shuco y podridoso" (ibid: 148).

Tamagás, variedad de serpiente. Nahuatismo, variedad de serpiente: "-iTata: brán tamagases?...” (ibid: 24).

Tata, padre, papá. De tahti 'padre': “Un día vido que su tata estaba furioso" (ibid: 19).

Tuco, trozo, pedazo. Nahuatismo: "En aquel tuco de cielo el sol metía un hombro" (ibid: 112).

Zacate, hierba, césped. De tsacat 'hierba, césped': “(...) ya perdido entre el zacate que lambía gozoso las paredes lisas" (ibid: 29).

Sin duda estos términos con raíces en el idioma náhuatl son testimonio de una herencia cultural muy significativa del país centroamericano y resultan cruciales para la caracterización de la variedad del español salvadoreño de Cuentos de barro.

\subsection{Interjecciones y modismos}

Por otra parte, el uso abundante de interjecciones, vocativos y frases idiomáticas contribuye también al propósito de recrear un lenguaje oral. Los diálogos de los personajes contienen múltiples ejemplos:

“-iA la puerca, con vos! ¡Cuchuyate contra yo, pué!...” (Salarrué, 1967: 25).

"—iPerdonáme, hermano!...-!Agüén!... ${ }^{13}$ ¿Y yo de qué?... No siazareye, que liace daño" (ibid: 92).

(ibid: 105).

“-iAgüén, qué fuéso?... ¡Amonós, vos!”

“-iAchís, O, ya maneció!...” (ibid: 105).

“-iPa que veya; demasiado milagrero el hijuepuerca!...” (ibid: 146).

“-iPues váyese al chorizo, istúpido, y jódase!...” (ibid: 174).
"-¿Cayen, O? --jSí, O!..., chimbolos y juilines, nomás. --jYa quizá va maneciendo, O!” (ibid: 104).

A propósito del uso del vocativo ó que observamos en los ejemplos y su conexión con el lenguaje oral, Geoffroy Rivas comenta: "A mi entender, este fenómeno ocurre cuando nos dirigimos a una persona que no vemos pero que está al alcance de nuestra voz, o cuando, aunque la veamos, está lejos y es necesario gritar: veníó, apurate'ó, corré'ó, etc." (1987: 30).

\subsection{Onomatopeya}

Finalmente, otro elemento importante utilizado por Salarrué para la recreación de la oralidad en su obra literaria es la onomatopeya. El diccionario de la Real Academia Española (2001: 1622) define la onomatopeya como la "Imitación o recreación del sonido de algo en el vocablo que se forma para significarlo". Así, a pesar de tratarse de un texto escrito, con el empleo de la onomatopeya se evoca la impresión de que se está oyendo a alguien contar una historia, como se aprecia en los muchos ejemplos:

"De noche se oiba el juí, jui de una hamaca" (Salarrué, 1967: 31).

"Los pocuyos, despenicados en la inmensidad, arrullaban la cuna de la noche con su triste 'oíeo, oíeo, oieo', que sonaba intermitente, como la paletada blanda del remo que va, va, va (...)" (ibid: 36).

"Sobre dos gruesas vigas colocaban las trozas dijuntas para tabliarlas con la sierra roncadora: ‘Jrum... Jrum... Jrum...!”’ (ibid: 112).

“(...) iban las yeguas de sangre, atropellándose unas con otras, soplando las narices valientes, la crin al cielo y el casco al suelo: ipatacán, patacán, patacán!” (ibid: 116).

“(...) se oyó el saltito de duende del tambor, llamando a los de la rogación: 'tom, tom, tom; tototom, tom, tom; tototom, tom, tom..." (ibid: 143).

De esta manera, por medio de la onomatopeya, el lector se sumerge en el ritmo de la historia y puede imaginar a los personajes imitando el ruido hecho por el vaivén de una 
hamaca, por el correr de unas yeguas o por una sierra al cortar madera.

Tomando en cuenta la estructura de la obra en su totalidad, podemos concluir que los abundantes recursos lingüístico-literarios desplegados por el autor de Cuentos de barro contribuyen a construir una representación literaria que retrata la vida cotidiana y el entorno físico y social del campesino indígena salvadoreño. La utilidad de la estilización dialectal en la representación literaria de una realidad determinada fue reconocida por Rosenblat desde hace tiempo al afirmar que: "La estilización del habla popular o coloquial puede constituir uno de los encantos de la novela, y contribuir a dar vida real a los personajes y a su ambiente" (1969: 79). Y el mismo Salarrué revela su propia intención de retratar el ambiente indígena-campesino lo más fielmente posible en el fragmento titulado "Tranquera", que sirve como introducción a su obra: "así, con las manos untadas de realismo; con toscas manotadas y uno que otro sobón rítmico, he modelado mis Cuentos de barro" (1967: 9). Lo que Salarrué denomina realismo sin duda tiene mucho que ver con la forma en que él consigue manejar y moldear el lenguaje y sus convenciones literarias para recrear el habla y la realidad social de un sector del pueblo salvadoreño a través de la manipulación de rasgos lingüísticos específicos, desarrollando, en las palabras de Barry (2001:182), "a coherent pattern of representation that acclimatizes the reader to the distinctions that characterize the language in the text without diverting attention from the story itself". Es así que Salarrué logra su cometido y recrea hábilmente su versión literaria del español rural salvadoreño en Cuentos de barro.

\section{Conclusión}

En conclusión, como se ha discutido, la recreación del dialecto salvadoreño en Cuentos de barro y la apariencia de oralidad que impregna dicha obra están estrechamente ligadas a la selección que el autor hace de los diversos rasgos lingüísticos que se combinan para producir el efecto deseado y así retratar más fielmente la realidad socio-económica y lingüística del campesino indígena salvadoreño. Por lo tanto, al realizar el estudio de un texto literario siempre resultará de gran utilidad identificar los elementos fonológicos, morfológicos, sintácticos y léxicos utilizados, ya que dichos elementos, combinados entre sí, contribuyen a evocar esa impresión de oralidad que nos ofrece la obra. Aunque queda mucho por hacer y habrá que continuar aplicando los avances de la teoría lingüística al estudio de otras obras de la literatura salvadoreña, el presente análisis de los principales rasgos lingüísticos de Cuentos de barro muestra de una manera explícita el complejo proceso de moldeado y alteración a que se somete el lenguaje en una obra como la de Salarrué en la que dialecto y oralidad van de la mano.

\section{Notas}

1. Todos los ejemplos presentados se transcriben tal como aparecen en la obra.

2. Para más sobre el dialecto visual, véase Barry (2001) y Nuessel (2000).

3. Hualde et al. (2010: 408) consideran que esto "es un fenómeno general en casi toda Latinoamérica".

4. Quesada Pacheco y Rivera Orellana (2013: 146) mencionan también el uso en el español de El Salvador de formas femeninas como parienta y testiga.

5. Hualde et al. (2010: 173) ubican a -ada y -al entre los sufijos más productivos del español en la derivación de sustantivos a partir de otros sustantivos.

6. Los puntos suspensivos que no están entre paréntesis no indican material omitido, sino que se muestran de la forma en que aparecen en la obra.

7. Según Stewart (1999: 97): “in the Catalan-speaking parts of Spain as well as the Canaries and large parts of Latin America, it is common to find the impersonal verb haber 'regularized' so that it agrees in the plural with its noun complement, e.g. Habian tres chicas (standard: Habia tres chicas)". 
8. Con respecto al orden de estos pronombres, Wheatley (2006: 187) expone lo siguiente: "Generalmente se usan las siglas RID para referirse al orden típico de los pronombres: reflexivo, indirecto y directo. Siguiendo esta regla, el pronombre reflexivo siempre va antes del pronombre de objeto directo o del indirecto, y el pronombre de objeto indirecto va antes del pronombre de objeto directo".

9. Aloyé equivale a: ya lo oye usted.

10. Chafe (1982) habla de fragmentación (fragmentation) al referirse a la falta de conectores entre ideas en el discurso, lo cual considera característico del lenguaje oral.

11. Se provee solo la acepción en que difieren del español normativo.

12. Las definiciones provienen del glosario incluido al final de Cuentos de barro y de Geoffroy Rivas (1987).

13. Agüén viene de ¡Ah buen! y equivale a: ¡Vaya!, ¡Anda!, ¡No faltaba más!

\section{Bibliografía}

Azcúnaga López, Raúl Ernesto. 2010. "Fonética del español salvadoreño". En: Miguel Quesada Pacheco (ed.) El español hablado en América Central: nivel fonético: 83-113. Madrid/Frankfurt: Iberoamericana/ Vervuert.

Azevedo, Milton M. 1991. "Literary dialect as an indicator of sociolinguistic conflict in Juan Marsé's El amante bilingüe". En: Journal of Interdisciplinary Literary Studies III (2): 125-136.

Azevedo, Milton M. 1995. "Linguistic features in the literary representation of Vernacular Brazilian Portuguese". En: Hispanic Linguistics VI/VII: 449-473.

Azevedo, Milton M. 2002. "Considerations on literary dialect in Spanish and Portuguese". En: Hispania LXXXV (3): 505-514.
Azevedo, Milton M. 2004. "Implicaciones pedagógicas de la representación literaria de la variación lingüística en español". En: Hispania LXXXVII (3): 464-475.

Baixauli Fortea, Inmaculada. 2000. "Las secuencias de historia". En: Antonio Briz et al. (eds.) ¿Cómo se comenta un texto coloquial?: 81-107. Barcelona: Editorial Ariel.

Barry, Betsy. 2001. “'It's hard fuh me to understand what you mean, de way you tell it': Representing language in Zora Neale Hurston's Their Eyes Were Watching God". En: Language and Literature X (2): 171-186.

Canfield, D. Lincoln. 1981.Spanish Pronunciation in the Americas. Chicago: The University of Chicago Press.

Canfield, D. Lincoln. 1988. El españolde América: Fonética. Trad. Joaquim Llisterri y Dolors Poch. Barcelona: Editorial Crítica.

Chafe, Wallace L. 1982. "Integration and involvement in speaking, writing, and oral literature". En: Deborah Tannen (ed.) Spoken and Written Language: Exploring Orality and Literacy: 35-53. Norwood, NJ: Ablex.

Geoffroy Rivas, Pedro. 1987. La lengua salvadoreña. 2a ed. San Salvador, El Salvador: Ministerio de Cultura y Comunicaciones.

Hualde, José Ignacio et al. 2010. Introducción a la lingüística hispánica. 2a ed. Cambridge: Cambridge University Press.

Ives, Sumner. 1971. "A theory of literary dialect". En: Juanita V. Williamson y Virginia M. Burke (eds.) A Various Language. Perspectives on American Dialects: 145-177. New York: Holt, Rinehart and Winston. 
Martínez Ruiz, Raquel. 2000. "La deixis". En: Antonio Briz et al. (eds.) ¿Cómo se comenta un texto coloquial?: 243-262. Barcelona: Editorial Ariel.

Mendoza, Martha. 2005. "Polite diminutives in Spanish: A matter of size?" En: Robin T. Lakoff y Sachiko Ide (eds.) Broadening the Horizon of Linguistic Politeness: 163173. Amsterdam: John Benjamins.

Mendoza, Martha. 2014. "Orality in literature: Cuban-American Spanish in La vida es un special 1.50 .75 by Roberto G. Fernández". En: Laura Callahan (ed.) Spanish and Portuguese across Time, Place, and Borders: 108-122. New York: Palgrave Macmillan.

Miranda, J. Alberto. 1994. La formación de palabras en español. Salamanca, España: Ediciones Colegio de España.

Moreno de Alba, José G. 1993. El español en América. 2a ed. México: Fondo de Cultura Económica.

Nuessel, Frank. 2000. Linguistic Approaches to Hispanic Literature. Ottawa: LEGAS.

Penny, Ralph. 1991. A History of the Spanish Language. Cambridge: Cambridge University Press.

Quesada Pacheco, Miguel Ángel. 2008. "El español de América Central ayer, hoy y mañana". En: Boletín de Filología XLIII: 145-174.

Quesada Pacheco, Miguel Ángel. 2010. "Prólogo". En: Miguel Quesada Pacheco (ed.) El español hablado en América Central: nivel fonético: 13-19. Madrid/Frankfurt: Iberoamericana/Vervuert.
Quesada Pacheco, Miguel Ángel y Erick Rivera Orellana. 2013. "Morfosintaxis del español de El Salvador". En: Miguel Ángel Quesada Pacheco (ed.) El español hablado en América Central: nivel morfosintáctico: 141-190. Madrid/ Frankfurt: Iberoamericana/Vervuert.

Real Academia Española. 2001. Diccionario de la lengua española. Tomo II. 22a ed. Madrid: Editorial Espasa Calpe, S. A.

Rosenblat, Ángel. 1969. Lengua literaria y lengua popular en América. Cuadernos del Instituto de Filología "Andrés Bello". Caracas: Universidad Central de Venezuela.

Salazar Arrué, Salvador. 1967. Cuentos de barro. 5a ed. San Salvador, El Salvador: Dirección General de Publicaciones del Ministerio de Educación.

Stewart, Miranda. 1999. The Spanish Language Today. London/New York: Routledge.

Tannen, Deborah. 1982. "Oral and literate strategies in spoken and written narratives". En: Language LVIII (1): 1-21.

Tannen, Deborah. 1987. "Repetition in conversation: toward a poetics of talk". En: Language LXIII (3): 574-605.

Turner, George W. 1973. Stylistics. New York: Penguin Books.

Wheatley, Kathleen. 2006. Sintaxis y morfología de la lengua española. Upper Saddle River, NJ: Pearson Education.

Zamora Munné, Juan C. y Jorge M. Guitart. 1982. Dialectología hispanoamericana. Salamanca, España: Ediciones Almar.

\section{(C) (1) $\Theta \Theta$}

Este obra está bajo una licencia de Creative Commons Reconocimiento-NoComercial-SinObraDerivada 4.0 Internacional. 